ISSN: 2231-3354

Received on: 03-02-2012

Revised on: 08-02-2012

Accepted on: 16-02-2012

DO: 10.7324/J APS.2012.2606

\section{Shyni Bemard}

Department of $\mathrm{P}$ harmaceutical

Chemistry, Malik Denar College of

Pharmacy, K asaragod, Kerala, Indi a.

\section{Molly Mathew}

Malik Deenar College of P harmacy, Kasaragod, Kerala, I ndi a.

\section{For Correspondence}

Shyni Bemard

Asst Professor,

Department of $P$ harmaceutical

Chemistry, M alik Denar College of

Pharmacy, K asaragod, Kerala, Indi a.

\section{Spectrophotometric method of estimation of atorvastatin calcium using sulfo-phospho-vanillin reaction}

\section{Shyni Bemard and Molly Mathew}

\begin{abstract}
A simple and sensitive visible spectrophotometric method has been developed for the determination of Atorvastatin (ATV) in pure form and in tablets using Sulfo-Phospho-Vanillin reagent.The methods is based on the reaction of atorvastatin with sulphuric acid to form carbonium ion,which subsequently react with vanillin phosphate ester and measuring the resulting purple coloured complex at $414 \mathrm{~nm}$. Under the proposed optimum condition, Beer's law was obeyed at the concentration range of $30-100 \mu \mathrm{g} / \mathrm{ml}$. The result of analysis of tablet was found to be $99.81 \%$. The good results of recovery studies showed that the co-formulated substances did not interfere with the determination. The method was validated according to ICH guidelines by performing linearity, accuracy, and precision, limits of quantification, limit of detection and selectivity.
\end{abstract}

Keywords: Atorvastatin, Spectrophotometry, Tablets,Vanillin.

\section{INTRODUCTION}

Lowering the concentration of low-density lipoprotein (LDL) cholesterol and raising high-density lipoprotein (HDL) cholesterol slows the progression of atherosclerosis. The Statins are the drugs of first choice for treating hyper cholesterolaemia. Statins should be considered for all patients, including the elderly, with coronary heart disease and occlusive arterial disease (British National Formulary., 2002). Atorvastatin calcium chemically [R-(R, R*)]-2-(4flurophenyl)- $\beta, \delta$-dihydroxy-5(1-methylethyl)-3-phenyl-4- [phenylamino) carbonyl]-1H-pyrrole-1heptanoic acid, calcium salt (2:1) trihydrate, is an inhibitor of HMG -CoA reductase, an enzyme involved in cholesterol biosynthesis (Clarke's Analysis of Drugs and Poisons in Pharmaceuticals.,2004). The chemical structure of Atorvastatin calcium is shown in Figure. 1. The drug has been demonstrated to be efficacious in reducing both cholesterol and triglycerides (Poswar et al., 1996 and Curtis et al., 2002).The effectiveness of atorvastatin in lowering cholesterol is dose-related. Atorvastatin calcium is not official in Indian Pharmacopoeia, British Pharmacopoeia, United States and European Pharmacopoeia. 
Literature survey revealed that very few sophisticated analytical methods such as HPLC (Atluntas et al., 2004 and Gowri et al., 2005), GC-MS (McKenney et al., 1998), LC-MS (Black et al., 1998), HPLC-Electron spray tandem mass spectrometry (Bullen et al., 1999) and HPTLC (Yadav et al., 2005) have been reported for the estimation of Atorvastatin calcium and its combinations from its formulations and biological fluid. The primary objective of the present investigation was to develop simple, precise and an accurate spectrophotometric method for the estimation of Atorvastatin calcium from its marketed formulations.

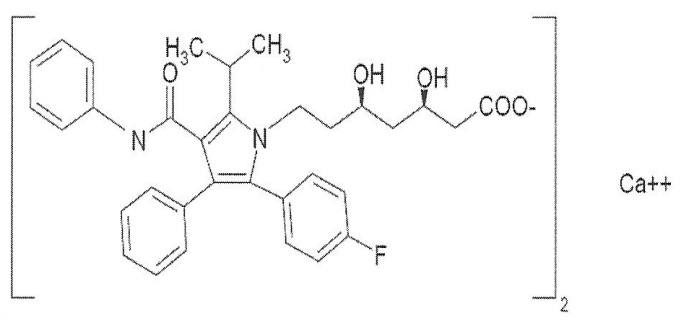

Fig. 1: Structure Of Atorvastatin Calcium.

\section{MATERIALS AND METHODS}

\section{Instrument}

Spectrophotometric analysis was carried out by using Jasco.V 550 UV-visible Spectrophotometer (Jasco Ltd, Japan) with $1 \mathrm{~cm}$ matched quartz cells

\section{Reagents and Chemicals}

Reference standard of atorvastatin was generous gift from Intas Pharmacetical Industry,Dehradun (India). Vanillin and Phosphoric acid were analytical grade obtained from Himedia Laboratories Mumbai and Methanol A.R and Sulphuric acid was purchased from Merck,Mumbai.

\section{Methods}

\section{Preparation of Phospho-Vanillin Reagent}

Dissolved $0.6 \mathrm{~g}$ of vanillin with $100 \mathrm{ml}$ water in a $100 \mathrm{ml}$ volumetric flask and makeup the volume with water (vanillin reagent). Mixed $35 \mathrm{ml}$ of vanillin reagent and $60 \mathrm{ml}$ of concentrated phosphoric acid, with constant stirring add $5.0 \mathrm{ml}$ of water and stored in a brown bottle at room temperature(Christopher et al., 1972).

\section{Preparations of Atorvastatin Standard Solutions}

$50 \mathrm{mg}$ of pure ATV was dissolved in $50 \mathrm{ml}$ of methanol and stirred for 15 minutes and the final volume was made up to 50 $\mathrm{ml}$ with methanol to prepare working concentrations of $1 \mathrm{mg} / \mathrm{ml}$ of ATV.

\section{Development of Atorvastatin-Sulfo-Phospho-Vanillin coloured complex}

To $1.5 \mathrm{ml}$ of Atorvastatin standard solution, taken in a boiling tube, $2.0 \mathrm{ml}$ of concentrated sulphuric acid was added, mixed the content well, added $5.0 \mathrm{ml}$ of Sulfo- Phospho-Vanillin reagent, placed in boiling water bath for 10min., cooled (Christopher et al., 1972) and transferred to a $25 \mathrm{ml}$ volumetric flask washed the test tube with small volume of methanol and transferred to the flask. The contents were mixed properly and the volume was made up to $25 \mathrm{ml}$ with methanol. The resulting solution had a concentration of $60 \mu \mathrm{g} / \mathrm{ml}$.

\section{Preparation of the Reagent Blank}

The reagent blank was prepared in the same manner as discussed omitting the standard drug solution.

\section{Study of the Spectral Characteristics}

The background correction for the instrument (Jasco.V 550) was done from $350-700 \mathrm{~nm}$ using a reagent blank. The purple coloured drug -reagent complex was then scanned through 350$700 \mathrm{~nm}$. The spectrum exhibited absorption maximum at $414 \mathrm{~nm}$.(Figure 3).

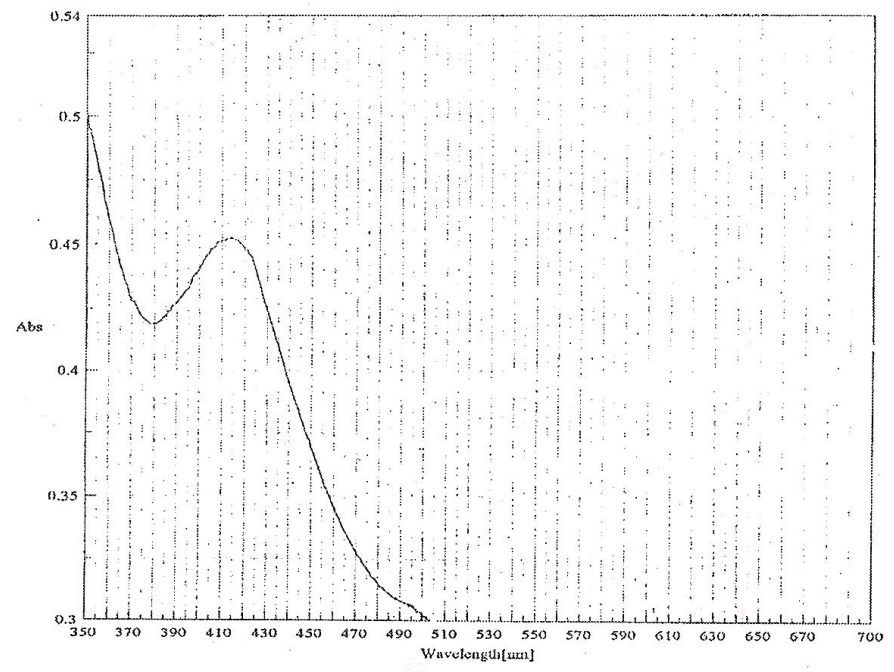

Fig. 3: spectrum of atorvastatin-reagent colour complex.

\section{Beer's Law Plot for Drug-Reagent Complex}

From the Atorvastatin standard solution 0.5, 0.75, 1.0, $1.25,1.5,1.75,2.0,2.25$ and $2.5 \mathrm{ml}$ were pipetted out into nine boiling tubes and the drug reagent colour complex was prepared as disussed. The contents were mixed properly and the volume was made up to $25 \mathrm{ml}$ with methanol. The absorbance of the solutions were measured at $414 \mathrm{~nm}$ against reagent blank. The Data obtained are given in Table. 1 and is graphically represented in (Figure 2).

Table. 1: Data for Beer's Law plot.

\begin{tabular}{cccc}
\hline $\begin{array}{c}\text { S. } \\
\text { No: }\end{array}$ & $\begin{array}{c}\text { Volume of ATV stock } \\
\text { solution(ml) }\end{array}$ & $\begin{array}{c}\text { Concentration of ATV in } \\
\text { final solution }(\boldsymbol{\mu g} / \mathbf{m L})\end{array}$ & $\begin{array}{c}\text { Absorbance } \\
\mathbf{a t} \mathbf{4 1 4} \mathbf{~ n m}\end{array}$ \\
\hline 1. & 0.50 & 20 & 0.056 \\
2. & 0.75 & 30 & 0.123 \\
3. & 1.0 & 40 & 0.224 \\
4. & 1.25 & 50 & 0.309 \\
5. & 1.5 & 60 & 0.412 \\
6. & 1.75 & 70 & 0.524 \\
7. & 2.0 & 80 & 0.620 \\
8. & 2.25 & 90 & 0.767 \\
9. & 2.0 & 100 & 0.879 \\
\hline
\end{tabular}




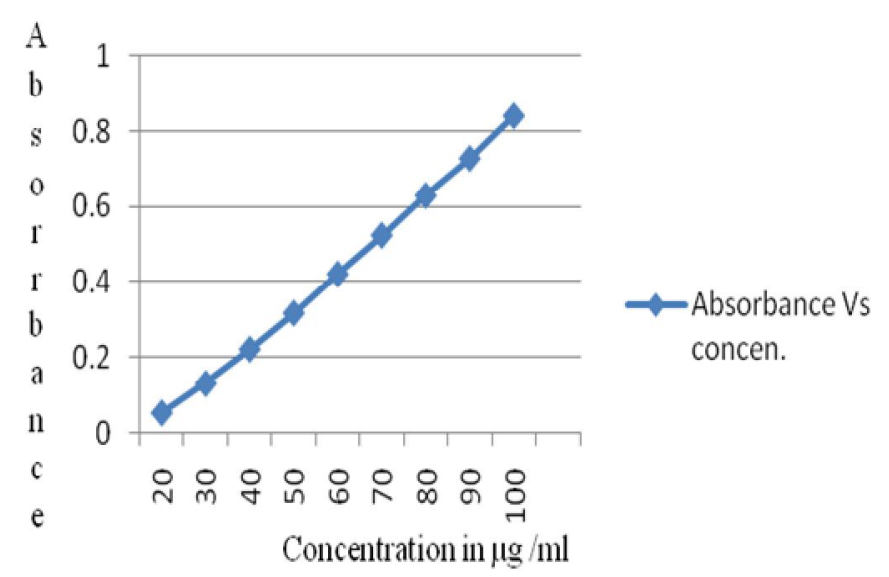

Fig. 2: beer's law plot.

\section{Standardisation of volume of the Reagent}

Sulfo-Phospho-Vanillin reagent was prepared and the drug-reagent complex was developed by adding different volumes of reagent and different volumes of sulphuric acid to varying concentrations of the Atorvastatin standard solution. To each tube containing drug volume of $0.75,1.0$ and $1.25 \mathrm{ml}$, added $3.0 \mathrm{ml}$, $5.0 \mathrm{ml}$ and $6.0 \mathrm{ml}$ volumes of reagent. The procedure was repeated with $1.0 \mathrm{ml}$ and $2.0 \mathrm{ml}$ volumes of sulphuric acid. It can be seen that the system obeys Beer's law when the volume of the reagent was $5.0 \mathrm{ml}$ and sulphuric acid volume was $2.0 \mathrm{ml}$. Hence $5.0 \mathrm{ml}$ of Phospho-Vanillin reagent and $2.0 \mathrm{ml}$ of concentrated sulphuric acid was taken as the optimum volumes for the method.

\section{Stability Profile of Drug-Reagent Complex}

The period over which the coloured complex gave a steady absorbance was investigated. Three different concentrations, ie. 30,40 and $50 \mathrm{mcg} / \mathrm{ml}$ were used for the study. The drugreagent complex was prepared and the absorbance of the solutions were measured at $414 \mathrm{~nm}$ at 15 minutes intervals for $1 \mathrm{hr}$ against reagent blank. The data obtained are given in Table-3.

Table. 3 : Data for stability profile of the drug-reagent complex.

\begin{tabular}{|c|c|c|c|c|c|c|}
\hline \multirow[t]{2}{*}{$\begin{array}{l}\text { S. } \\
\text { No. }\end{array}$} & \multirow{2}{*}{$\begin{array}{l}\text { Concentration of } \\
\text { Atorvastatin Calcium } \\
\mu \mathrm{g} / \mathrm{mL}\end{array}$} & \multicolumn{5}{|c|}{$\begin{array}{c}\text { Absorbance at } 414 \mathrm{~nm} \\
\text { At } 15 \text { minutes time intervals }\end{array}$} \\
\hline & & $2 \mathrm{~min}$ & $15 \mathrm{~min}$ & 30min & $45 \mathrm{~min}$ & $60 \mathrm{~min}$ \\
\hline 1 & 30 & 0.123 & 0.116 & 0.114 & 0.113 & 0.110 \\
\hline 2 & 40 & 0.223 & 0.222 & 0.217 & 0.218 & 0.218 \\
\hline 3 & 50 & 0.310 & 0.311 & 0.312 & 0.308 & 0.307 \\
\hline
\end{tabular}

\section{Procedure for analysis of tablet formulation}

Twenty tablets of Lipitor 10mg (Pfizer) was purchased from local market, accurately weighed and finely powdered. The weight of tablet equivalent to $25 \mathrm{mg}$ was accurately weighed out and extracted using methanol. The volume was finally made up to $25 \mathrm{ml}$ with methanol. The resulting solution had a concentration of $1 \mathrm{mg} / \mathrm{ml}$ (solution A). Accurately pipetted out 1.0 and $1.25 \mathrm{ml}$ of solution $\mathrm{A}$ in to two boiling tubes, prepared the drug reagent complex as discussed and made up the volume with alcohol. The solutions had final concentration of $40 \mu \mathrm{g} / \mathrm{ml}$ and $50 \mu \mathrm{g} / \mathrm{ml}$ respectively. The absorbance of each solution was measured at $414 \mathrm{~nm}$ using reagent blank and the amount of drug present in the sample solutions were obtained from the slope and intercept values obtained from the calibration curve (Table 1). The experiments were repeated three times to check its reproducibility. The results of analysis of tablet formulations were recorded in Table 4.

\section{Validation of the proposed Method:}

The method was validated according to ICH guidelines for validation of analytical procedures in order to determine the linearity, sensitivity, precision, robustness and accuracy for the analyte (ICH Q2B., 1994).

\section{Linearity and sensitivity}

Under optimum conditions, a linear relation was obtained between absorbance and concentration of ATV in the range 30$100 \mu \mathrm{g} / \mathrm{ml}$ (Fig. 2). The calibration graph is described by the equation:

$$
\mathrm{Y}=\mathrm{a}+\mathrm{bX}
$$

where $\mathrm{Y}=$ absorbance, $\mathrm{a}=$ intercept, $\mathrm{b}=$ slope and $\mathrm{X}==$ concentration, obtained by the method of least squares. The correlation coefficient, intercept and slope for the calibration data, sensitivity parameters such as apparent molar absorptivity and Sandell's sensitivity values, the limits of detection and limit of quantification were summarized in Table 2. The limits of detection (LOD) and limit of quantification (LOQ) were calculated according to the $\mathrm{ICH}$ guidelines using the formulas:

$$
\mathrm{LOD}=3.3 \sigma / \mathrm{s} \text { and } \mathrm{LOQ}=10 \sigma / \mathrm{s} \text {, }
$$

where ' $\sigma$ ' is the standard deviation of five reagent blank determinations and ' $s$ ' is the slope of the calibration curve.

Table. 2: Optical Characteristics of coloured complex for the developed method.

\begin{tabular}{cc}
\hline \multicolumn{2}{c}{ Parameters } \\
\hline Y= a+bX & $\mathrm{y}=0.010385 \mathrm{X}-0.18754444444$ \\
Molar absorptivity & $1.0385 \times 10^{4} . \mathrm{L} / \mathrm{mol} . \mathrm{cm}$. \\
Sandell's sensitivity & 0.11237 \\
Limit of detection (LOD), $\mu \mathrm{g} / \mathrm{ml}$ & $\left(\mu \mathrm{g} / \mathrm{cm}^{2} / 0.001 /\right.$ absorbance unit) \\
Limit of quantification (LOQ), $\mu \mathrm{g} /$ & 1.8 \\
ml & 5.6 \\
Intercept (a) & -0.1875 \\
Slope (b) & 0.01038 \\
Regression coefficient (r) & 0.99865 \\
\hline
\end{tabular}

*Limit of determination as the weight in $\mu \mathrm{g}$ per $\mathrm{ml}$ of solution, which corresponds to an absorbance of $\mathrm{A}=0.001$ measured in a cuvette of cross-sectional area $1 \mathrm{~cm}$ and $1=1 \mathrm{~cm}$.

\section{Precision and accuracy}

Intra-day precision and accuracy of the proposed method were evaluated by replicate analysis $(n=5)$ of calibration standards at three different concentration levels in the same day. Inter-day precision and accuracy were determined by assaying the calibration standards at the same concentration levels on five consecutive days. Precision and accuracy were based on the calculated relative standard deviation (RSD, \%) and relative error (RE, \%) of the found concentration compared to the theoretical one, respectively (Table 5). 
Table. 4: Data of analysis of tablets.

\begin{tabular}{|c|c|c|c|c|c|c|}
\hline $\begin{array}{c}\text { Concentration } \\
\mu \mathrm{g} / \mathrm{ml}\end{array}$ & $\begin{array}{c}\text { Absorbance * } \\
\text { At } 414 \text { nm }\end{array}$ & \% Label claim & $\begin{array}{l}\text { Active content } \\
\text { per tablet }(\mathrm{mg})\end{array}$ & $\begin{array}{l}\text { Mean\% Label } \\
\text { claim }\end{array}$ & Standard deviation & Standard Error \\
\hline 40 & 0.221 & 99.80 & 9.980 & \multirow{2}{*}{99.81} & 0.001549 & 0.0006324 \\
\hline 50 & 0.309 & 99.82 & 9.982 & & 0.001673 & 0.0006831 \\
\hline
\end{tabular}

*Mean of three determinations.

Table. 5: Evaluation of intra-day and inter-day accuracy and precision (RE: relative error; RSD: relative standard deviation).

\begin{tabular}{|c|c|c|c|c|c|c|}
\hline \multirow{2}{*}{ ATV taken $\mu \mathrm{g} / \mathrm{ml}$} & \multicolumn{3}{|c|}{ Intra-day accuracy and precision } & \multicolumn{3}{|c|}{ Inter-day accuracy and precision } \\
\hline & ATV found $\mu \mathrm{g} / \mathrm{ml}$ & RE, \% & RSD, $\%$ & ATV found $\mu \mathrm{g} / \mathrm{ml}$ & RE, \% & RSD, $\%$ \\
\hline 40 & 39.28 & 1.80 & 1.80 & 39.4 & 1.52 & 1.38 \\
\hline 50 & 49.7 & 1.52 & 1.63 & 49.7 & 0.60 & 1.31 \\
\hline 60 & 59.04 & 1.60 & 1.58 & 58.99 & 1.60 & 1.60 \\
\hline
\end{tabular}

\section{Recovery studies}

The accuracy and validity of the proposed method were further ascertained by performing recovery studies. Pre-analyzed tablet powder was spiked with pure ATV at three concentration levels (50, 100 and $150 \%$ of that in tablet powder) and the total was found by the proposed method. The added ATV recovery percentage values ranged between 106.80 and $111.8 \%$ with the standard deviation of $1.24-1.48 \%$ (Table 6) indicating that the recovery was good and the co-formulated substances did not interfere with the determination.

Table. 6: Data of Recovery studies.

\begin{tabular}{cccc}
\hline $\begin{array}{c}\text { ATV in } \\
\text { tablet } \\
\boldsymbol{\mu} \mathbf{g} / \mathbf{m L}\end{array}$ & $\begin{array}{c}\text { Pure ATV } \\
\text { added } \\
(\mathbf{s p i k e d}) \boldsymbol{\mu g} / \mathbf{m L}\end{array}$ & $\begin{array}{c}\text { Total concentration } \\
\text { found } \boldsymbol{\mu g} / \mathbf{m L}\end{array}$ & $\begin{array}{c}\text { Pure ATV recovered* } \\
(\text { Mean } \pm \text { S.D) }(\mathbf{n}=\mathbf{3})\end{array}$ \\
\hline 39.9 & 5 & 45.49 & $111.80 \pm 1.3$ \\
39.9 & 10 & 50.81 & $109.10 \pm 1.48$ \\
39.9 & 15 & 55.92 & $106.8 \pm 1.24$ \\
\hline
\end{tabular}

*Average of three determinations

\section{RESULTS AND DISCUSSION}

The "sulfo-phospho-vanillin" reaction for the determination of total serum lipids was first introduced by Chabrol and Charonnat (Press med.,1937) It has been suggested that the reaction requires a carbon-carbon double bond (Frings et al.,1970). The reaction apparently is specific for unsaturated organic compounds. Major function of the sulfuric acid is to hydrolyze the lipid esters. Here, an unsaturated double bond accepts a proton from sulfuric acid (strong acid) to form a highly reactive carbonium ion. The ion is efficiently formed at $100^{\circ} \mathrm{C}$ (lower temperatures lead to considerably less reaction), on cooling, the ion so formed is stable for at least several hours. Vanillin reagent is prepared in water, but when it is mixed with concentrated phosphoric acid reacts with the hydroxyl group of vanillin to produce an aromatic phosphate ester before use. The colour reaction takes place in three steps (Figure 4): In the first step the unsaturated compounds react with sulfuric acid to produce a carbonium ion, in second step vanillin reacts with phosphoric acid to produce an aromatic phosphate ester and in third step the carbonium ion reacts with the activated carbonyl group of phospho- vanillin to produce a charged colored complex that is stabilized by resonance and absorbs maximally at about 414 nm(Zoeliner et al.,1962). Alcohols with more than two carbon atoms also react and are readily dehydrated by concentrated sulfuric acid to unsaturated compounds which subsequently react as just described (Morrison et al., 1962). It is evident that there is good agreement between the amounts estimated and those claimed by the manufacturers. The mean percentage label claims of marketed tablets (Table 4) were very close to 100 with low values of standard deviation and standard error which confirms the accuracy of the proposed method. Accuracy and precision of the proposed method were further confirmed by the mean percentage recovery values (106 to 111 ), which were close to100 with low values of standard deviation (Table.6). The proposed method for the determination of ATV showed molar absorptivity of $1.0385 \mathrm{x}$ $10^{4} \mathrm{~L} / \mathrm{mol} . \mathrm{cm}$. and Sandell's sensitivity of $0.11237\left(\mu \mathrm{g} / \mathrm{cm}^{2} /\right.$ 0.001/ absorbance unit). Linear regression of absorbance on concentration gave the equation $\mathrm{Y}=0.010385 \mathrm{X}-0.18754444444$ with a correlation coefficient $r=0.99865$ (Table 2).
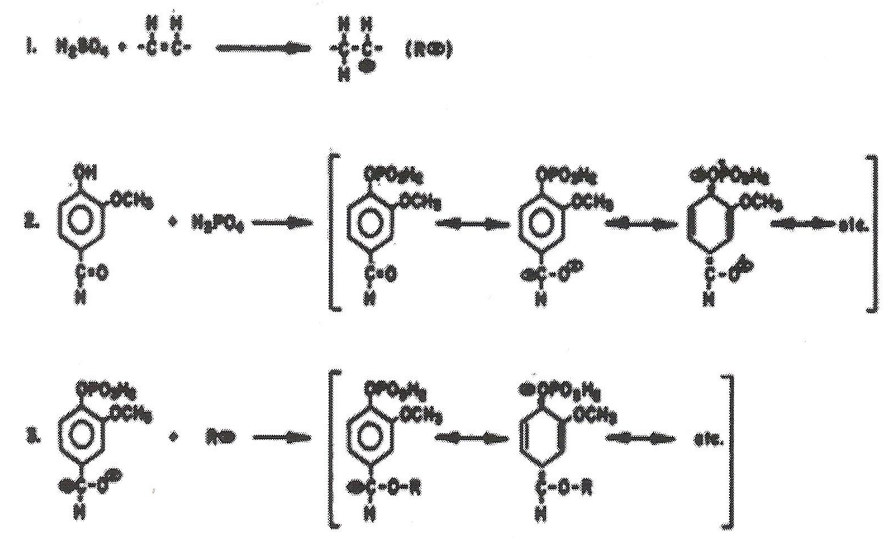

Fig. 4: proposed reaction sequence for sulfo-phospho-vanillin reaction.

\section{CONCLUSION}

A new visible spectrophotometric method is developed which is economic, simple, precise, sensitive and rapid and hence can be employed for the routine analysis for the estimation of atorvastatin from marketed formulations.

\section{ACKNOWLEDGEMENTS}

The authors thank Intas Pharmacetical Industry,Dehradun (India) for the gift sample of atorvastatin calcium and also grateful to the management of Malik Deenar College of Pharmacy, Kasaragod, Kerala for providing the facilities for the research wok. 


\section{REFERENCES}

Altuntas T G., Erk N. Liquid chromatographic determination of Atorvastatin in bulk drugs, tablets and human plasma .J. Liq. Chro.2004; 27 (1): 83

Black A E., Sinz M W., Hayes R N., and Woolf T F. Metabolism and excretion studies in mouse after single and multiple oral doses of the 3-hydroxyl-3- methyl glutaryl- CoA reductase inhibitor atorvastatin ; Drug Metab. Dispos.1998 ; 26: 755.

2.12 .

British National Formulary. $54^{\text {th }}$ ed.(September 2007) Section:

Bullen W W., Miller R A., Hayes R N.Development and validation of a high performance liquid chromatography tandem mass spectrometry assay for atorvastatin, orthohydroxy atorvastatin and parahydrxy Atorvastatin in human, dog and rat plasma; Amer. Soc. Mass Spectrum.1999; 10: 55.

Chabrol E., and Charonnat R. Une nouvele reaction pour l'etudes des lipides: L'oleidemie. Presse Med.1937; 45:1713.

Christopher S Frings., Ted W Fendley., Ralph T Dunn., and Cecelia A Queen. Improved determination of total serum lipids by the Sulfo-Phospho-Vanillin Reaction.Clinical Chemistry.1972;18 (7):673.

Curtis,Sutter,Walkar \& Hoffmann (2002) Integrated Pharmacology (2nd edn). ( p-30) Mosby International,Ltd.

Frings C S., Dunn R T. A colorimetric method for determination of total serum lipids based on the sulfo-phosphovanihin reaction. Amer. J. Clin. Pathol.1970; 53:89).
Gowari Sankar D., Raju M S M., Sumanth., Kalyan S., Latha P $\mathrm{V}$ M. Estimation of Atorvastatin by high performance liquid chromatography in pure and pharmaceutical dosage form. Asian J. Chem.2005; 17 (4) : 2571. (1994) 1-5.

ICH Q2B, Text on Validation of Analytical Procedures. Geneva

McKenney J M., Mccormik L S., Weis S., Koren M., Kotonek S., Black D M. A Randomized Trial of the Effects of Atorvastatin and Niacin in Patients with Combined Hyperlipidemia or Isolated Hypertriglyceridemia.Amer. J. Med.1998; 104: 137.

Moffat A C., Osselton M D; Widdop B.( 2004) .Clarke's Analysis of Drugs and Poisons in Pharmaceuticals, body fluids and Postmortem material.2004.( $3^{\text {rd }}$ edn) Part 2(p 654) The Pharmaceutical Press: Great Britain.

Morrison, R. T., and Boyd, R. N.,(1968).Organic Chemistry $2^{\text {nd }}$ edn). Boston, Mass (p.161) Allyn \& Bacon, Inc.

Poswar E L., Radulovic L L., Cilla D D., Whitfield L R., Sedman A J.Tolerance and pharmacokinetics of single-dose atorvastatin, a potent inhibitor of HMG-CoA reductase, in healthy subjects. J. Clin. Pharmacol.1996; 36: 728.

Yadav S S., Mhaske D V., Kakad A B., Patil B D., Kadam S S., Dhaneshwar SR. A simple and sensitive HPTLC method for the determination of content uniformity of Atorvastatin calcium tablets. Indian J. Pharm. Sci.2005; 67(2): 182.

Zoeliner N., Kirsch K., Uber die.Quantitative Bestimmung von Lipoiden mittels der vielen naturlischen Lipoiden gemeinsamen sulfophosphovanillin Reaction. Z. Gesamte Exp. Med.1962; 135 : 545. 